OPEN ACCESS

Edited by:

Nurshad Ali

Shahjalal University of Science and Technology, Bangladesh

Reviewed by:

Charalampos Proestos,

National and Kapodistrian University of Athens, Greece

Gael Janine Mearns,

Auckland University of Technology,

New Zealand

Farhad Vahid,

Luxembourg Institute of

Health, Luxembourg

${ }^{*}$ Correspondence:

Agnieszka Woźniak

awozniak@pzh.gov.pl

Katarzyna Stoś

kstos@pzh.gov.p

Specialty section: This article was submitted to

Nutrition and Food Science

Technology,

a section of the journal

Frontiers in Nutrition

Received: 06 July 2021

Accepted: 28 September 2021

Published: 27 October 2021

Citation:

Stoś K, Woźniak A, Rychlik E,

Ziótkowska I, Głowala A and

Ottarzewski M (2021) Assessment of Food Supplement Consumption in

Polish Population of Adults.

Front. Nutr. 8:733951.

doi: 10.3389/fnut.2021.733951

\section{Assessment of Food Supplement Consumption in Polish Population of Adults}

\author{
Katarzyna Stoś*, Agnieszka Woźniak*, Ewa Rychlik, Izabela Ziółkowska, Aneta Głowala \\ and Maciej Ottarzewski
}

Department of Nutrition and Nutritional Value of Food, National Institute of Public Health NIH - National Research Institute, Warsaw, Poland

Introduction: In recent years, there has been a great interest in food supplements. However the use of food supplements can be associated with the risk of excessive intake of vitamins or minerals which may have adverse health effects.

Objective: Assessment of food supplement consumption in the adult population in Poland.

Materials and Methods: The study was conducted on 1,831 adults (913 men, 918 women) from which 178 (59 men, 119 women) food supplement users were selected. The consumption of food supplements were assessed by the 24-h recall repeated two times and the food propensity questionnaire (FPQ).

Results: $10 \%$ of the subjects consumed food supplements during the 12 months prior to the study (6\% of men, $13 \%$ of women) and among users $68 \%$ (79\% of men and $88 \%$ of women) in the day before the survey. Most respondents (44\%) used vitamin supplements during the year. More men than women (27 vs. $11 \%, p=0.0059$ ) used mineral supplements while more women than men used vitamin and mineral supplements (31 vs. $8 \%, p=0.0008)$. The most frequently supplemented vitamins were: $\mathrm{B}_{6}(58 \%), \mathrm{C}$ (53\%), and D (47\%) and minerals were: magnesium (43\%), zinc (34\%), and iron (29\%). More women than men supplemented vitamin B6 (71 vs. 40\%, $p=0.0012$ ), vitamin D (54 vs. $36 \%, p=0.0061$ ) and magnesium (49 vs. $34 \%, p=0.0075$ ). Intake of riboflavin, pantothenic acid and manganese were higher in the group of men (respectively: $3.3 \mathrm{mg}$ \pm 6.0 vs. $1.4 \mathrm{mg} \pm 0.3, p=0.0329 ; 9.4 \mathrm{mg} \pm 5.6$ vs. $6.1 \mathrm{mg} \pm 2.0, p=0.0357 ; 2.2 \mathrm{mg}$ \pm 0.9 vs. $1.3 \mathrm{mg} \pm 0.6, p=0.0080$ ) but intake of vitamin $\mathrm{D}$ was higher in the group of women (15.7 $\mu \mathrm{g} \pm 20.4 \mathrm{vs.} 33.1 \mu \mathrm{g} \pm 26.4, p=0.0085)$. In many cases, the intake of vitamins and minerals from food supplements covered the Dietary Reference Values for these nutrients in $100 \%$. In some persons the intake of biotin, vitamin $B_{12}, C, B_{6}$, riboflavin, niacin was higher than the reference values several dozen times. The intake of vitamins and minerals exceed $U L$ in a few cases relating to vitamin $\mathrm{B}_{6}$ and magnesium.

Conclusions: A minority of adults in Poland used food supplements. However, those products were a significant source of vitamins and minerals. Intake of vitamins and minerals from food supplements should be monitored.

\footnotetext{
Keywords: food supplements, vitamins, minerals, vitamin intake, mineral intake
} 


\section{INTRODUCTION}

Diet is one of the key factors determining human health and it should cover the organism's need for nutrients. Well balanced diet, rich in fruits and vegetables, that are source of vitamins and other nutrients may reduce the risk of chronic diseases, such as cardiovascular diseases, cancers, diabetes and osteoporosis $(1,2)$. In turn, micronutrient deficiency can have wide-range negative health impacts (3). The WHO states, that the best way of preventing micronutrient malnutrition is to ensure consumption of a balanced diet that is adequate in every nutrient (4). To help people eat better, healthy eating guidelines have been developed in many countries around the world (5). They provide evidence-based statements on food choices to meet nutritional requirements and reduce the risk of prevailing chronic disease (6). However, recommendations for taking food supplements (foodstuff which are concentrated sources of nutrients i.e., minerals and vitamins or other substances with a nutritional or physiological effect) have also been developed for certain population groups, where scientific evidence indicates a benefit of such supplementation. For example, it is commonly recommended to supplement diet with vitamin D in all population groups of Central Europe countries, including Poland $(7,8)$. Other example are pregnant women who have increased requirements for certain nutrients, like folic acid, supplementation of which is recommended in order to reduce the risk of neural tube defects in infants (9). An elderly people may also need supplementation, as absorption of some nutrients becomes less efficient with aging, but the need for the supplementation should be confirmed by a doctor $(10,11)$. For vegans, vitamin $B_{12}$ must be obtained from regular use of vitamin $B_{12}$-fortified foods, otherwise a daily vitamin $B_{12}$ supplement is needed (12).

However, the constantly expanding market of supplements and their non-prescription status make them generally available for all population groups (13). Young people who consume an unbalance diet, instead of improving eating habits, use food supplements with the belief that it will reduce the risk of serious health complications $(14,15)$. Adult food supplement users perceive supplements as an easy and safe way to stay healthy (16, 17). Although the issues related to the composition and labeling of food supplements have been legally regulated at the EU level (18), there are still elements for which no legislative solutions have been developed. In Poland, the provisions of Directive 2002/46/EC are implemented by the Food and Nutrition Safety Act (19) and the Regulation of the Minister of Health on the composition and labeling of food supplements (20). The law defines, inter alia, what vitamins and minerals and what their chemical forms may be used in the food supplements. However, there are still no maximum levels of vitamins and minerals in supplements set at the EU level. The law only says what criteria should be taken into account when setting such levels. These are: upper safe levels of vitamins and minerals established by scientific risk assessment based on generally accepted scientific data, taking into account, as appropriate, the varying degrees of sensitivity of different consumer groups, the intake of vitamins and minerals from other dietary sources and the reference intakes of vitamins and minerals for the population $(18,20)$. The lack of regulations in the above scope makes it possible to use high doses of vitamins and minerals in food supplements, and unjustified consumption of vitamin and mineral products may lead to exceeding the safe levels of these nutrients $(21,22)$. In that context the food supplement consumption in the adult population in Poland was assessed. Firstly it was estimated what percentage of Polish adults consumed food supplements. Then, the detailed examination only among people who reported the consumption of these products was made. In order to check if there was a risk of excessive intake of vitamins and minerals only from food supplements the composition of food supplements used by the subjects as well as the amounts of vitamins and minerals they consumed within these products were analyzed. These amounts have been compared to the Dietary Reference Values and Tolerable Upper Intake Levels (UL) in order to assess whether food supplements were a significant and safe source of these nutrients. The result on intake of vitamins and minerals from all dietary sources including base diet will be analyzed and published separately.

\section{MATERIALS AND METHODS}

\section{Study Population}

The data was collected as part of the national dietary crosssectional survey in Poland on the representative sample of the adolescent and adult population which was conducted from July 2019 to February 2020. The survey included assessment of nutrition, nutritional status and physical activity and was carred out according to the EFSA guidance on the EU Menu methodology $(23,24)$.

The study was conducted after obtaining the approval of the Bioethics Committee at the Institute of Food and Nutrition in Warsaw. Participation in the study was voluntary, each respondent gave the written consent to participate in it.

The sample selection for the study was done by the stratified sampling method using the PESEL (In Polish: Powszechny Elektroniczny System Ewidencji Ludności) system taking into account such demographic details as age, gender and place of residence. There were two parts of the sample selection procedure: the stratification of the Polish population and the random selection of individuals. Data was collected in all 16 voivodeships of Poland. The number of subjects living in cities and villages was corresponding to the structure in the particular voivodeship. The following exclusion criteria for the participation in the study were adopted:

- subjects that were hospitalized and/or were following an enteral and parenteral nutrition because of their health conditions,

- subjects, whose mental condition made impossible to obtain reliable information (neurodegenerative diseases, drunkenness, state after taking drugs and other stimulating substances).

The number of subjects selected using a stratified sampling method was 10 times higher than the one assumed, in order to prevent unforeseen circumstances or refusal and ensure 
the planned number of people to be finally studied. If a selected person refused to participate in the survey, withdrew from the study or met the criteria for exclusion from the study, the next person in the group was chosen. Only subjects who participated in all parts of the study were included. The interviewers were obliged to make repeated attempts to contact the randomly selected respondent until the interview was successfully completed or the definitive inability to complete it was confirmed (hard refusal, prolonged absence of the respondent during the survey). Attempts were made to contact 4,249 persons. The study involved $57 \%$ of persons who were invited (response rate). Subjects that fall under the exclusion criteria was not taken into account when calculating the above mentioned response rate.

The complete set of data was collected from 2,432 adolescents and adults (1,214 males and 1,218 females). There were 1,831 adults (913 men and 918 women) in that group. Pregnant or breastfeeding women were not subjects of the study. From among adults, persons who declared in the survey that they use food supplements were selected (213 persons). We excluded 35 participants because the products they had indicated as food supplements were drugs, not food supplements.

Therefore, for the assessment of food supplement consumption 178 adults (59 men, 119 women) were included.

\section{Data Collection}

The survey methodology followed the EFSA EU Menu guidance recommendations $(23,24)$. Socio-demographic data like age, gender, place of residence, education level, labor activity, economic status (respondent's self-assessment) and health status (respondent's self-assessment) were collected using the questionnaire. For this purpose, the interviewers used the CAPI technique (Computer Assisted Personal Interview).

The consumption of food supplements was assessed by the food propensity questionnaire (FPQ) and 24-h recall repeated two times to obtain both data on the consumption of food supplements during the 12 months prior to the study and data on the current consumption of these products (in the day before the survey).

The FPQ included questions about the food supplement consumption during the 12 months prior to the study. Respondents were asked about trade name, brand, manufacturer and composition of consumed supplements. They also defined how often particular food supplements were consumed during the 12 months prior to the study (every day, a few times a week, few times a month, periodically or occasionally).

Questions on food supplement consumption were also included in the $24 \mathrm{~h}$ recall which was used to collect food consumption data. The dietary recall included information about the time and place of consumption of the meal, kind of the meal and portion size. Interviewers also asked if the respondent consumed any supplements in the last day, if yes, respondent was asked about its name, brand, producer, composition, as well as a single dose. The data was entered into the Internet platform software by interviewers. Only data on the consumption of food supplements were used in this study. The consumption of other food products was not analyzed.
In the case of multi-component food supplements or consumption of several products, it was very helpful to take by interviewers pictures of the packaging for consumed food supplements (if the respondent had it) and completed data after interview.

The questionnaire on socio-demografic details and FPQ were completed during the first interview at respondent's home. The first 24-h recall was also conducted during this visit. The second interview was conducted a minimum of 7 days but no longer than 14 days after the first interview, in such a way as to cover equal proportion of all days in the week. Data on vitamins and minerals intake from food supplements were assessed by calculating the mean across two days from 24-h dietary recall.

Due to the composition, food supplements consumed by subjects were divided into 5 groups: "vitamins only", "minerals only", "vitamins and minerals", "vitamins and/or minerals and other ingredients" and "other" (supplements containing ingredients other than vitamins and minerals). The other ingredients were, such as: fish oils, omega 3 fatty acids, plant ingredients (citrus bioflavonoids, lutein, lycopene, linseed oil, Oenothera oil, extracts of various plants, among others: green tea, ginger, dandelion, guarana, Ginkgo biloba, Panax ginseng, Rosa canina, Equisetum arvense, Morus alba, Uva-ursi, Urtica dioica, Yerba mate, Plantago ovata), amino acids (L-alanine, Larginine, L-aspartic acid, L-cysteine, L-glutamic acid, L-glycine, L-histidine, L-isoleucine, L-leucine, L-methionine), collagen, hyaluronic acid.

The intake of vitamins and minerals by each person was compared with Dietary Reference Values for the Polish population (25) to Estimated Average Requirement (EAR) or Adequate Intake (AI), regarding age and gender and also to Tolerable Upper Intake Levels (UL) established for these nutrients by European Food Safety Authority (EFSA) (21, 26-28).

\section{Statistical Analysis}

The results were statistically tested using a computer software PQStat 1.8.2. In order to verify whether the distribution was normal, the Shapiro-Wilk test was used. The data distributions weren't normal so the significance of differences was assessed using the Mann-Whitney $U$ test for non-parametric data and the chi-square test for qualitative data. For all analyses, the significance level $\alpha=0.05$ was assumed. Relationships between the gender and other parameters were examined using the Spearman's correlation (non-parametric data).

\section{RESULTS}

\section{Characteristic of Subjects}

Ten percent of the 1,831 subjects consumed food supplements ( $6 \%$ of men and $13 \%$ of women) during the 12 months prior to the study. The average age of subjects consuming food supplements was $54.8 \pm 19.5$ (18-96) years and it was similar in men and women $(55.9 \pm 20.3(18-89)$ vs. $54.2 \pm 19.1$ (1896), $p=0.3857$ ). The greatest number of men consuming such products was recorded in the age group of 65 years and over (42\%) while the greatest number of women consuming food supplements was observed in the age group of $18-30$ years (35\%). 
However, that difference was not statistically significant. Most of the respondents had an upper secondary education (42\%) and they were mainly retirees and pensioners (46\%). Compared to women, men were more likely to work physically and less mentally $(p=0.0076)$. The economic status of the greatest number of respondents was "neither good nor bad" (52\%) or "good" (35\%). Also, many subjects described their health status as "neither good nor bad" (39\%) or "good" (39\%). There were no statistically significant differences between men and women both in case of economic status and health status (Table 1).

\section{Food Supplement Consumption During the 12 Months Prior to the Study}

The greatest number of subjects ( $76 \%$ in total, $80 \%$ of men and $75 \%$ of women) used only one food supplement but a significant percentage of subjects (18\% in total, $14 \%$ of men and $20 \%$ of women) declared consumption of two such products during the 12 months prior to the study. From 1 to $2 \%$ of subjects in total reported consuming more food supplements (3-9 products). Most men and women consumed food supplements every day. Much fewer subjects reported taking supplements several times a week. There were no statistically significant differences between men and women in the frequency of consumption of food supplements during 12 months prior to the study (Table 2).

Most respondents used vitamin supplements during the year. A significant relationship was observed between gender and the consumption of mineral food supplements ( $\mathrm{rs}=-0.2064, p=$ 0.0057 ) and vitamin and mineral food supplements ( $\mathrm{rs}=0.2507$, $p=0.0007)$. More men than women ( 27 vs. $11 \%, p=0.0059)$ used mineral supplements while more women than men used vitamin and mineral supplements (31 vs. $8 \%, p=0.0008$ ) (Figure 1).

\section{Food Supplement Consumption in the Day Before the Survey}

Among subjects using food supplements, 68\% (79\% of men and $88 \%$ of women) declared consumption of these products in the day before the survey. The most of the respondents used one product ( $86 \%$ in total, $79 \%$ of men, $88 \%$ of women) but some consumed 2 (respectively: 10, 16, and 7\%) or three (respectively: 4,5 , and $4 \%$ ) products a day. The food supplements containing vitamins and/or minerals and other ingredients were consumed the most frequently in the day before the survey. $\mathrm{T}$ There were no statistically significant differences between percentage of men and women consuming particular types of food supplements ( $p$ $\geq 0.05$ ) (Figure 2).

\section{Assessment of Vitamin and Mineral Intake From Food Supplements}

In case of vitamins, the most subjects supplemented vitamin $\mathrm{B}_{6}(58 \%)$, vitamin C (53\%) and vitamin D (47\%). The most frequently supplemented minerals were magnesium $(43 \%)$, zinc (34\%) and iron (29\%). More women than men supplemented vitamin $\mathrm{B}_{6}$ (71 vs. $40 \%, p=0.0012$ ), vitamin $\mathrm{D}$ (54 vs. $36 \%, p$ $=0.0061)$ and magnesium ( 49 vs. $34 \%, p=0.0075)$ (Figure 3 ).

The vitamins and minerals intake was very differential. Intake of riboflavin, pantothenic acid and manganese was higher in the group of men ( $p=0.0329 ; p=0.0357 ; p=0.0080$, respectively) but intake of vitamin D was higher in the group of women $(p$ $=0.0085)$ (Tables 3, 4). Food supplements were a significant source of vitamins and minerals in the diets of the respondents. In many cases, they covered the dietary reference values (EAR or $\mathrm{AI}$ ) for these nutrients in $100 \%$. Compared to men, intake of vitamin $\mathrm{D}$ higher than AI value in women was more likely ( $p=$ 0.0074) (Figures 4, 5). In each respondent it was calculated what percentage of the EAR or AI values was the intake of particular vitamins and minerals from food supplements. The percentage of EAR or AI was very differential and on average was ranged from 5\% (potassium) to $478 \%$ (biotin). In some persons the vitamin intake was higher than the EAR or AI values several dozen times: biotin 83 times, vitamin $B_{12} 50$ times, vitamin $C 31$ times, riboflavin, niacin and vitamin $B_{6} 23$ times. A significant relationship was observed between gender and percentage of the EAR or AI values which was the intake of vitamin $\mathrm{D}(\mathrm{rs}=0.3661$, $p=0.0055)$, calcium ( $\mathrm{rs}=0.3804, p=0.0458$ ), and copper ( $\mathrm{rs}$ $=-0.3994, p=0.0288$ ). In women, intake of vitamin $\mathrm{D}$ and calcium constituted a greater percentage of EAR or AI values, and intake of copper was a smaller percentage of EAR values than in men ( $p=0.0108, p=0.0479, p=0.0389$, respectively) (Table 5).

The intake above UL in a few cases relating to vitamin $\mathrm{B}_{6}{ }^{-}$ 1 person (woman) and magnesium -3 persons (two men and one woman) was observed. Moreover intake of vitamin $\mathrm{B}_{6}$ and vitamin $\mathrm{D}$ was equal to the UL values, respectively in one man and two women.

\section{DISCUSSION}

According to our data from the survey presented in this manuscript the rate of adults using food supplements in the Polish population in $2019-2020$ was $6 \%$ in men and 13\% in women. These data apply only to preparations classified as food supplements. Preparations classified as OTC drugs were not included in this analysis.

In 2000, the first representative survey of the dietary intake of the entire population were carried out in Poland (21). These studies also estimated the frequency of using food supplements without taking OTC drugs into account. The survey from 2000 showed that food supplements were used by $11 \%$ of men, and $18 \%$ of women $(29,30)$.

Both in our survey from 2019-2020 and in the cited studies from 2000 (21), food supplements were used more often by females than by males.

In the survey from 2000, it was shown that supplementation did not significantly increase the average intake of most minerals and vitamins in the population. It increased only the average intake of iron, nicotinic acid, vitamin $\mathrm{B}_{6}$ and vitamin $\mathrm{E}$ in women and vitamin $\mathrm{E}$ in men (29).

According to our survey from 2019-2020 the percentage of respondents using food supplements was small. However, in the diet of users, supplements were an important source of nutrients.

Vitamins $B_{6}, C, D$ and magnesium were nutrients most often taken in the form of food supplements. Vitamin $B_{6}, D$ and 
TABLE 1 | Characteristic of subjects.

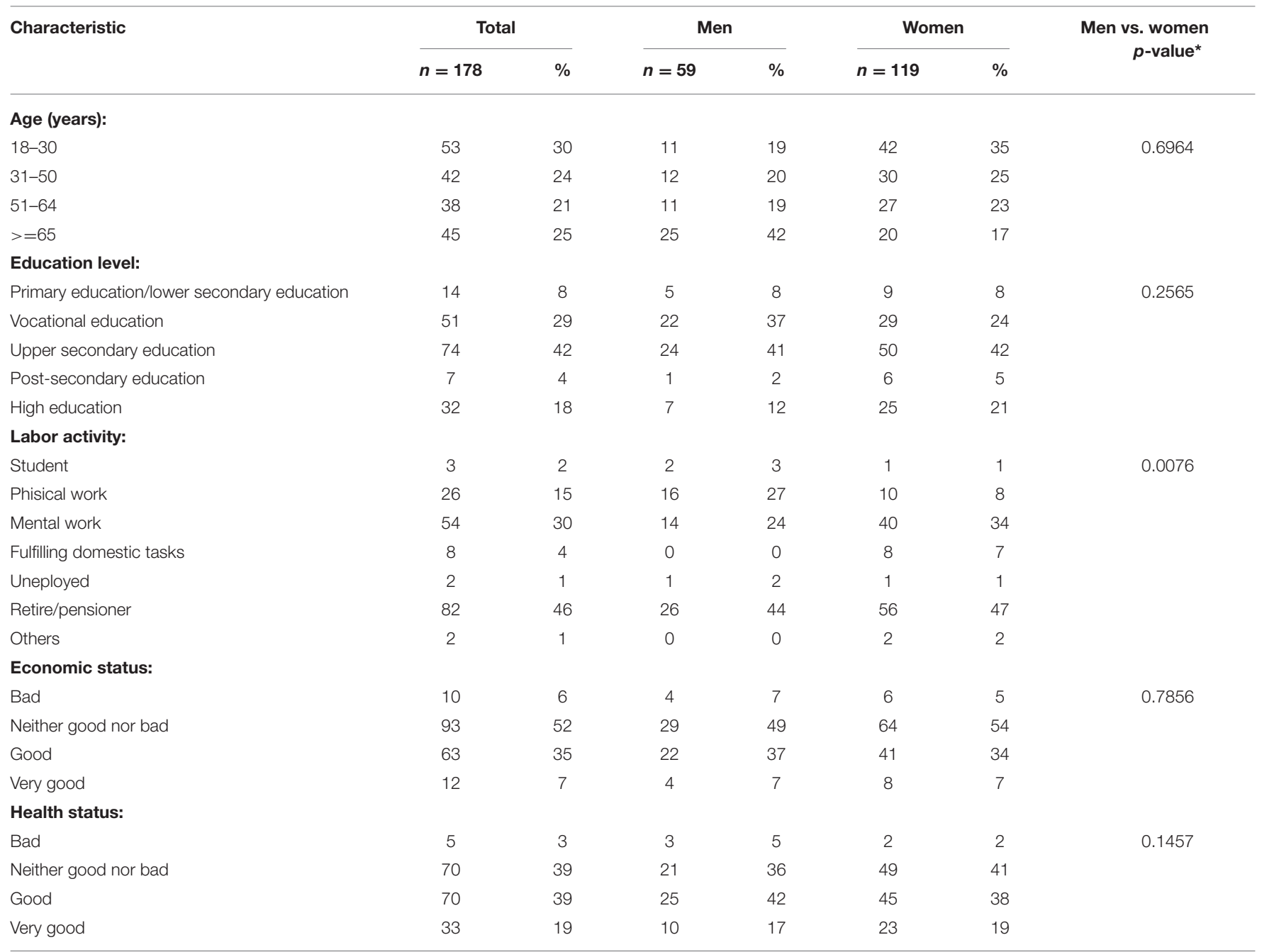

${ }^{*}$ chi-square test.

TABLE 2 | Frequency of food supplement consumption during the 12 months prior to the study.

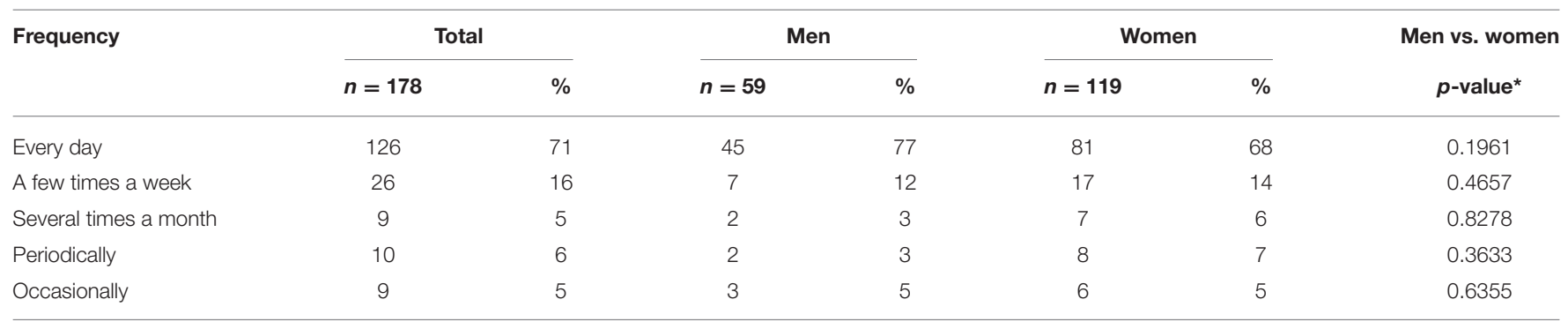

* chi-square test.

magnesium were taken more frequently by women than men. The average content of most nutrients in food supplements was quite high compared to the Dietary Reference Values (DRVs). However, the amounts of calcium, magnesium, phosphorus and potassium taken from supplements were not so high compared to the DRVs. Taking into account the median, the amount of vitamin D in men's diets from supplements was much lower than AI.

Certain population groups in Poland may use food supplements much more often (31-35). For example, in the years 2011-2012, dietary intake studies were carried out, taking into account food supplement use in Warsaw population aged 


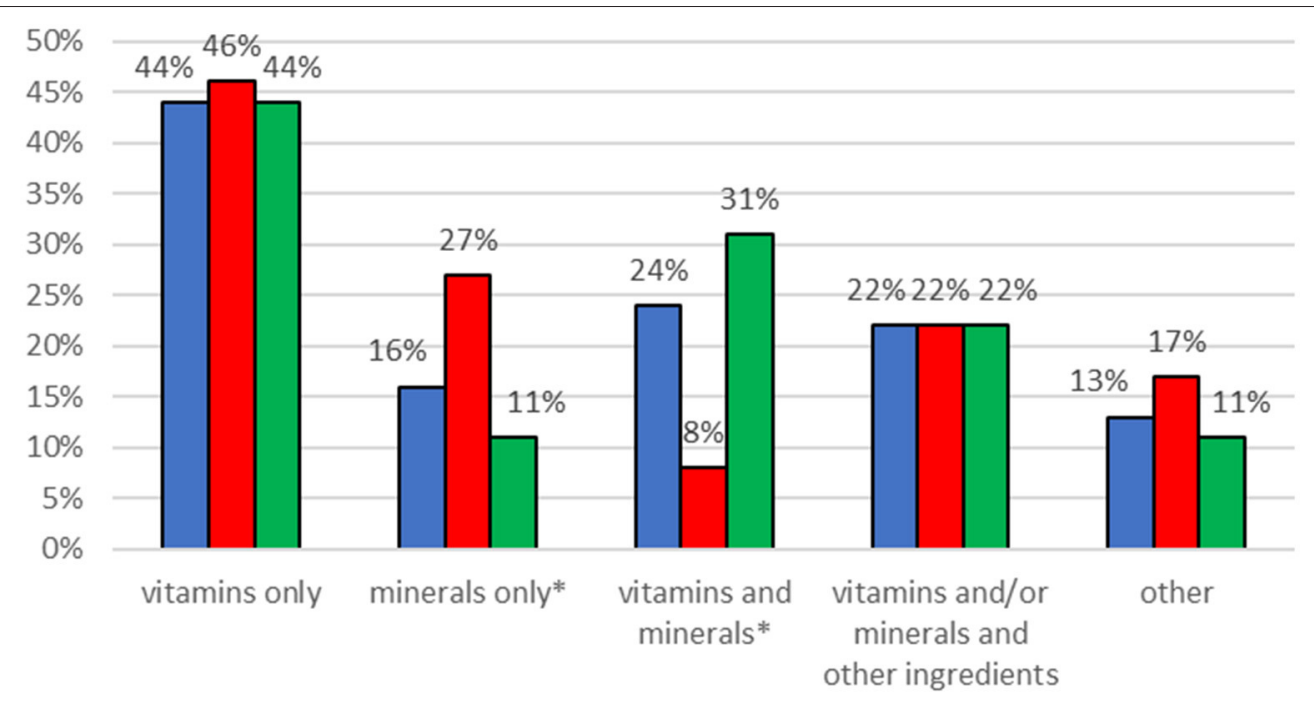

口Total aMen $\square$ Women

FIGURE 1 | Type of food supplements consumed during the 12 months prior to the study. * statistically significant difference, chi-square test, $p<0.05$.

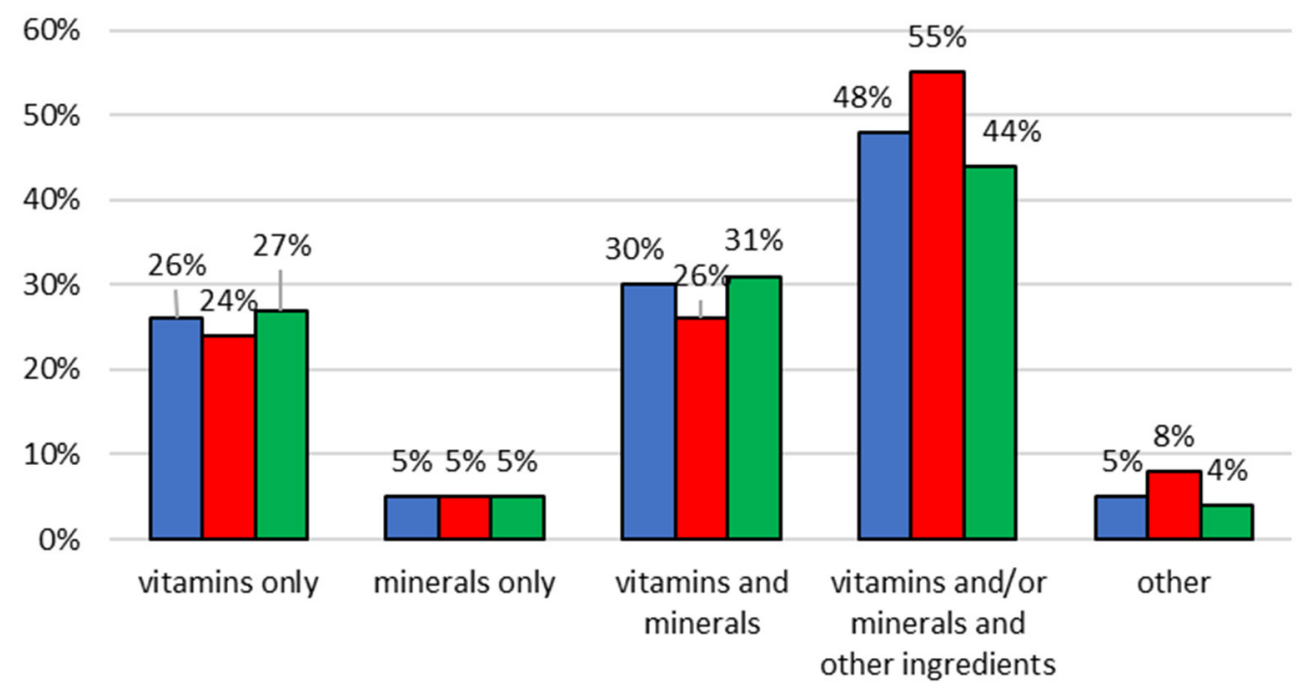

Total $\square$ Men $\square$ Women

FIGURE 2 | Type of food supplements consumed in the day before the survey.

20-74 years. Subjects supplemented their diets with vitamins and minerals quite often. The rate of food supplement users was higher in women (40\%) than in men (31\%). Subjects with higher education level and the highest income used supplements more often than those with primary education or the lowest income. Using food supplements containing vitamin $\mathrm{D}$, thiamine and folic acid contributed to better coverage of the requirements for these vitamins (31).

Another survey conducted in 2012 in students of the University of Rzeszow showed that the majority of respondents
- 71.5\% used food supplements. However, supplements have not always been used regularly; almost $40 \%$ of men and $30 \%$ of women consumed it occasionally. The most commonly used were food supplements containing vitamins, less often those containing minerals (32).

The use of supplements was also frequent in the group of subjects consisting mainly of young people, including the students of Medical University of Lublin. Food supplement consumption was reported by $77.84 \%$ of participants, however, $24.82 \%$ of women and $28.57 \%$ of men used them regularly. The 


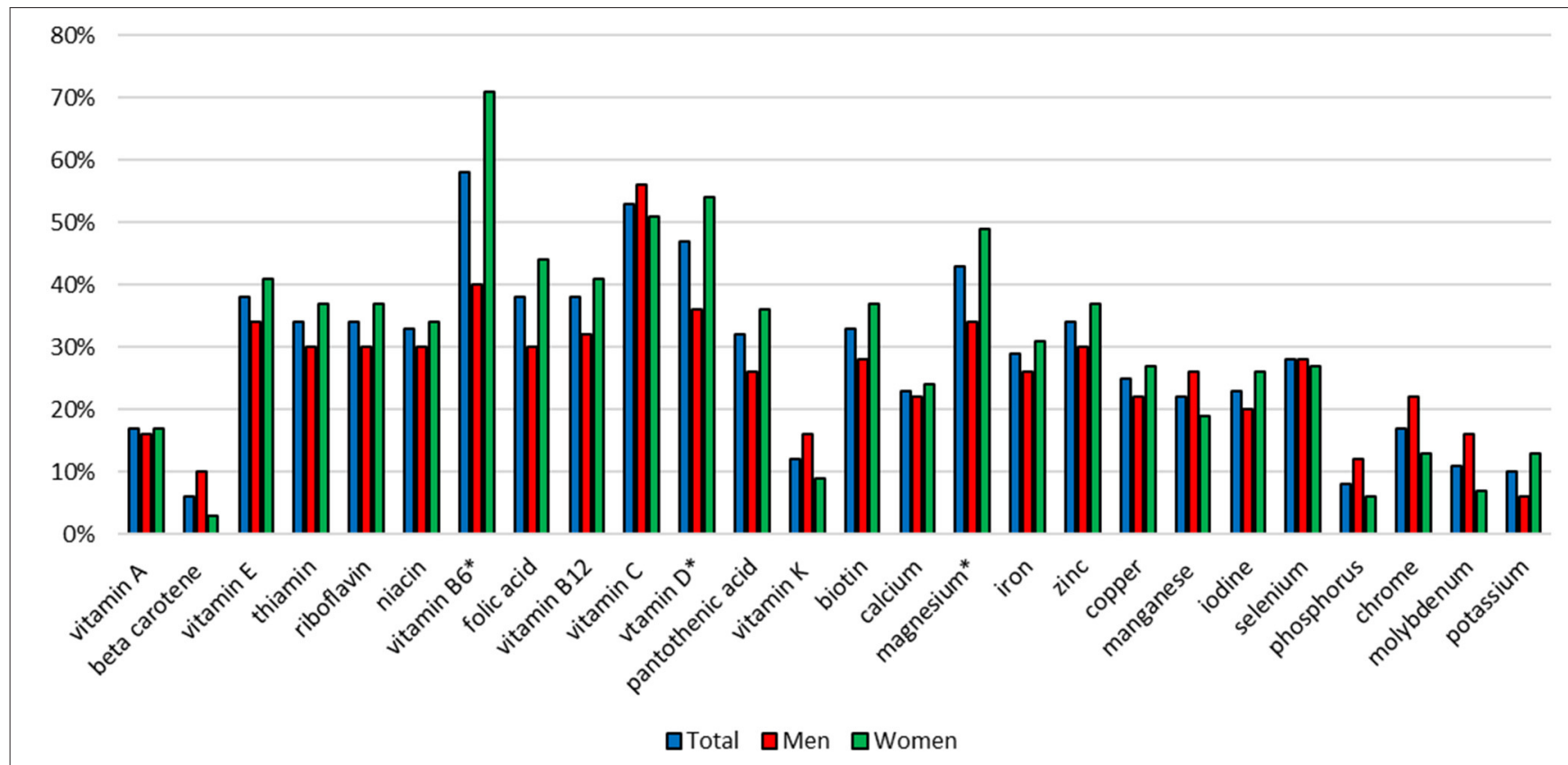

FIGURE 3 | Percentage of subjects supplementing particular vitamins and minerals. *statistically significant difference, chi-square test, $p<0.05$.

TABLE 3 | Intake of vitamins from food supplements.

\begin{tabular}{|c|c|c|c|c|c|c|c|c|c|c|}
\hline \multirow[t]{2}{*}{ Vitamins } & \multicolumn{3}{|c|}{ Total } & \multicolumn{3}{|c|}{ Men } & \multicolumn{3}{|c|}{ Women } & \multirow{2}{*}{$\begin{array}{c}\text { Men vs. } \\
\text { women } \\
\text { p-value* }\end{array}$} \\
\hline & Median & Mean \pm SD & Min-max & Median & Mean \pm sd & Min-max & Median & Mean \pm sd & Min-max & \\
\hline Vitamin A (RE. $\mu \mathrm{g})$ & 800.0 & $655.0 \pm 182$ & 300.0-800.0 & 600 & $612.5 \pm 188.5$ & $300-800$ & 800 & $683.3 \pm 180.1$ & $400-800$ & 0.3333 \\
\hline Beta carotene $(\mu \mathrm{g})$ & 200.0 & $1116.0 \pm 1655.4$ & $12.0-4000.0$ & 200 & $1520.0 \pm 1841.7$ & $200-4,000$ & 106 & $106.0 \pm 132.9$ & $12-200$ & 1.0000 \\
\hline Vitamin E (TE. mg) & 12.0 & $14.1 \pm 14.0$ & $3.6-100.0$ & 12 & $18.1 \pm 22.0$ & $5-100$ & 12 & $11.7 \pm 4.9$ & $3.6-30$ & 0.5015 \\
\hline Thiamin (mg) & 1.1 & $1.9 \pm 3.8$ & $0.3-25.0$ & 1.4 & $3.1 \pm 6.1$ & $0.65-25$ & 1.1 & $1.1 \pm 0.3$ & $0.33-1.7$ & 0.0564 \\
\hline Riboflavin (mg) & 1.4 & $2.1 \pm 3.7$ & $0.4-25.0$ & 1.8 & $3.3 \pm 6.0$ & $0.75-25$ & 1.4 & $1.4 \pm 0.3$ & $0.42-2.1$ & 0.0329 \\
\hline Niacin (NE. mg) & 16.0 & $17.7 \pm 6.3$ & $4.8-36.0$ & 20 & $20.0 \pm 7.4$ & $8.5-36$ & 16 & $16.2 \pm 5.1$ & $4.8-32$ & 0.0651 \\
\hline Vitamin $B_{6}(\mathrm{mg})$ & 1.4 & $2.7 \pm 4.5$ & $0.4-30.0$ & 1.4 & $3.4 \pm 5.5$ & $0.7-25$ & 1.7 & $2.4 \pm 4.1$ & $0.4-30$ & 0.9362 \\
\hline Folic acid $(\mu \mathrm{g})$ & 200.0 & $296.1 \pm 198.3$ & $60.0-800.0$ & 200 & $278.0 \pm 123.0$ & $150-600$ & 200 & $304.9 \pm 227.4$ & $60-800$ & 0.5720 \\
\hline Vitamin $B_{12}(\mu \mathrm{g})$ & 2.5 & $5.0 \pm 14.6$ & $0.7-100.0$ & 2.5 & $8.9 \pm 24.3$ & $0.67-100$ & 2.5 & $2.8 \pm 1.8$ & $0.8-10$ & 0.3368 \\
\hline Vitamin C (mg) & 83.5 & $310.8 \pm 455.5$ & 15.0-2000.0 & 120 & $470.4 \pm 586.9$ & $15-2000$ & 80 & $186.7 \pm 267.4$ & $24-1,000$ & 0.0835 \\
\hline Vitamin D ( $\mu \mathrm{g})$ & 10.0 & $27.5 \pm 25.8$ & $2.5-100.0$ & 5 & $15.7 \pm 20.4$ & $2.5-60$ & 50 & $33.1 \pm 26.4$ & $5-100$ & 0.0085 \\
\hline Pantothenic acid (mg) & 6.0 & $7.3 \pm 3.9$ & $1.8-25.0$ & 7.5 & $9.4 \pm 5.6$ & $3-25$ & 6 & $6.1 \pm 2.0$ & $1.8-12$ & 0.0357 \\
\hline Vitamin $\mathrm{K}(\mu \mathrm{g})$ & 30.0 & $33.2 \pm 9.3$ & $25.0-50.0$ & 30 & $34.4 \pm 9.8$ & $25-50$ & 30 & $31.7 \pm 9.3$ & $25-50$ & 0.4777 \\
\hline Biotin $(\mu \mathrm{g})$ & 50.0 & $143.3 \pm 388.9$ & $15.0-2500.0$ & 62.5 & $65.5 \pm 22.8$ & $25-112.5$ & 50 & $185.2 \pm 480.1$ & $15-2,500$ & 0.9639 \\
\hline
\end{tabular}

SD, standard deviation; *Mann-Whitney $U$ test.

subjects consumed mainly products containing only vitamins or vitamins and minerals, less probiotics and products containing only minerals (33).

In 2015 study conducted among 205 Polish adults (general population) and 49 pregnant women or planning pregnancy showed that $54 \%$ of respondents of both sexes from the general population used food supplements. About half of the respondents declared consumption of food supplements every day. Food supplements were more often used by pregnant women and those planning to become pregnant (89 and
$56 \%$, respectively) (34). Frequent food supplement consumption was also observed in another study in the group of women during pregnancy and women becoming pregnant (82 and $41 \%$, respectively) (35). In our study pregnant women were not included.

Data on food supplement use in Poland vary depending on the group. Surveys of the representative population for the country: from 2000 (29) and described in this manuscript from 2019-2020 showed a lower proportion of supplement users than surveys of target groups (31-35). However, the 
TABLE 4 | Intake of minerals from food supplements.

\begin{tabular}{|c|c|c|c|c|c|c|c|c|c|c|}
\hline \multirow[t]{2}{*}{ Minerals } & \multicolumn{3}{|c|}{ Total } & \multicolumn{3}{|c|}{ Men } & \multicolumn{3}{|c|}{ Women } & \multirow{2}{*}{$\begin{array}{c}\text { Men vs. } \\
\text { women } \\
\text { p-value* }\end{array}$} \\
\hline & Median & Mean \pm sd & Min-max & Median & Mean \pm sd & Min-max & Median & Mean \pm sd & Min-max & \\
\hline Calcium (mg) & 162.0 & $256.5 \pm 263.2$ & $66.0-1000.0$ & 162 & $196.7 \pm 146.6$ & $66-600$ & 160 & $295.2 \pm 315.3$ & $80-1,000$ & 0.9812 \\
\hline Magnesium (mg) & 100.0 & $110.5 \pm 68.6$ & $30.0-400.0$ & 100 & $119.4 \pm 100.2$ & $30-400$ & 100 & $106.1 \pm 47.1$ & $56.3-300$ & 0.5537 \\
\hline Iron (mg) & 5.0 & $10.3 \pm 13.3$ & $1.0-56.0$ & 5 & $7.1 \pm 4.2$ & $2.1-14$ & 5.5 & $12.2 \pm 16.3$ & $1-56$ & 0.8261 \\
\hline Zinc (mg) & 12.5 & $7.1 \pm 4.1$ & $1.0-20.0$ & 5 & $7.0 \pm 5.3$ & $1-20$ & 6.3 & $7.2 \pm 3.3$ & $1.5-12.5$ & 0.5058 \\
\hline Copper (mg) & 0.5 & $0.6 \pm 0.4$ & $0.2-1.5$ & 0.7 & $0.8 \pm 0.3$ & $0.5-1.5$ & 0.5 & $0.5 \pm 0.4$ & $0.15-1$ & 0.0536 \\
\hline Manganese (mg) & 2.0 & $1.7 \pm 0.9$ & $0.6-4.0$ & 2 & $2.2 \pm 0.9$ & $1-4$ & 1 & $1.3 \pm 0.6$ & $0.6-2$ & 0.0080 \\
\hline lodine $(\mu \mathrm{g})$ & 100.0 & $118.8 \pm 39.5$ & 50.0-200.0 & 100 & $100.0 \pm 20.4$ & $75-150$ & 125 & $129.2 \pm 43.9$ & 50-200 & 0.0613 \\
\hline Selenium ( $\mu \mathrm{g})$ & 30.0 & $38.5 \pm 21.5$ & $8.0-100.0$ & 34.1 & $45.4 \pm 26.8$ & 8-100 & 30 & $33.3 \pm 15.5$ & $8.3-55$ & 0.2320 \\
\hline Phosphorus (mg) & 125.0 & $136.2 \pm 42.9$ & 105.0-257.0 & 125 & $121.7 \pm 8.2$ & $105-125$ & 125 & $158.0 \pm 66.0$ & $125-257$ & 1.0000 \\
\hline Chrome $(\mu \mathrm{g})$ & 40.0 & $45.2 \pm 38.4$ & $6.0-200.0$ & 40 & $47.1 \pm 52.3$ & $6-200$ & 40 & $42.8 \pm 8.3$ & $25-50$ & 0.1130 \\
\hline Molybdenum $(\mu \mathrm{g})$ & 50.0 & $47.1 \pm 20.6$ & $12.0-100.0$ & 50 & $53.1 \pm 20.9$ & $25-100$ & 50 & $37.4 \pm 17.9$ & $12-50$ & 0.2124 \\
\hline Potassium (mg) & 150.0 & $169.6 \pm 127.8$ & 40.0-320.0 & 150 & $200.0 \pm 86.6$ & 150-300 & 40 & $159.4 \pm 141.8$ & 40-320 & 1.0000 \\
\hline
\end{tabular}

$S D$, standard deviation; *Mann-Whitney $\cup$ test.

$120 \%$

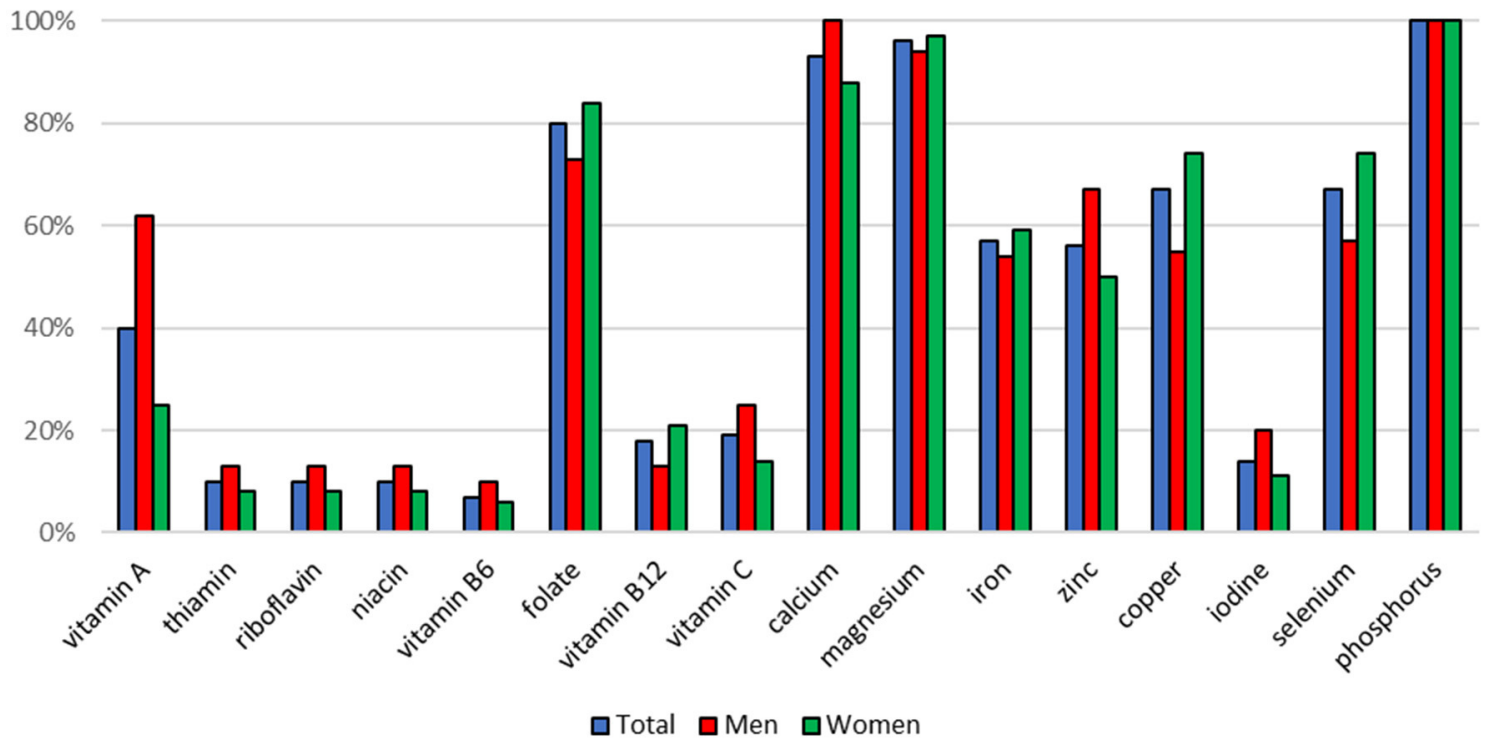

FIGURE 4 | Percentage of people whose intake of vitamins and minerals from food supplements was lower than the EAR value.

differences in data may be due to the fact that some authors could include OTC drugs containing vitamins and minerals into supplements.

Surveys conducted in Poland show that women use food supplements more often than men $(29,31)$, which was also confirmed by our study. Also, higher income, higher education level and living in large cities are conducive to using food supplements $(31,34)$. The relationship between the level of education and consumption of supplements may be confirmed by the relatively high proportion of food supplement users among students $(32,33)$.
In our study, the majority of supplement users ( $80 \%$ of males and $71 \%$ of females) consumed them every day. Less regularity was noted in other groups $(32,33)$. Both in the nationwide population and in other studied groups, products containing vitamins and/or minerals were used most often (29, 32, 33). Food supplements most often provided vitamin D and magnesium $(31,34)$.

Studies conducted in various European counties showed that the level of food supplement consumption was differential (from 8 to $60 \%)$. Food supplements were most often taken by the Danes ( $51 \%$ of men and $60 \%$ of women). Supplementation was also 


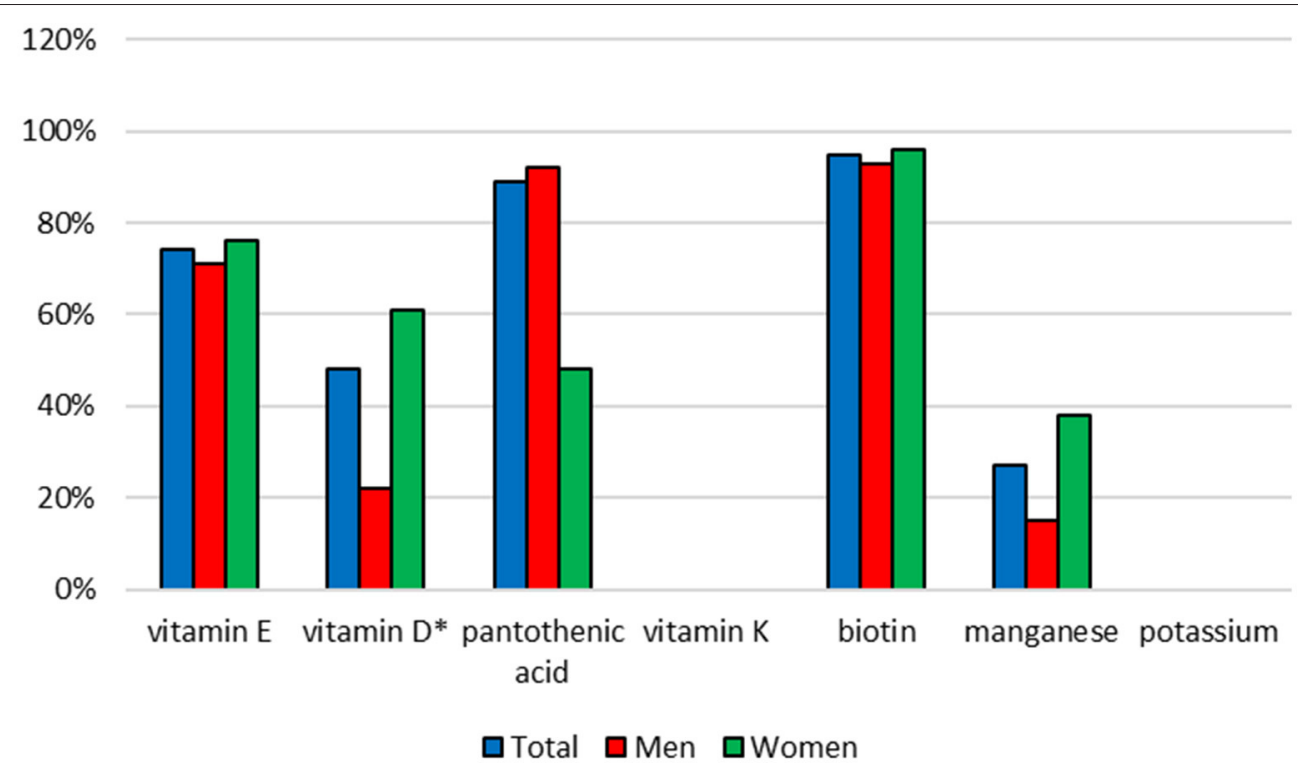

FIGURE 5 | Percentage of people whose intake of vitamins or minerals from food supplements was higher than the Al value. *statistically significant difference, chi-square test, $p<0.05$.

TABLE 5 | Percentage of EAR or Al which was the intake of vitamins and minerals from food supplements.

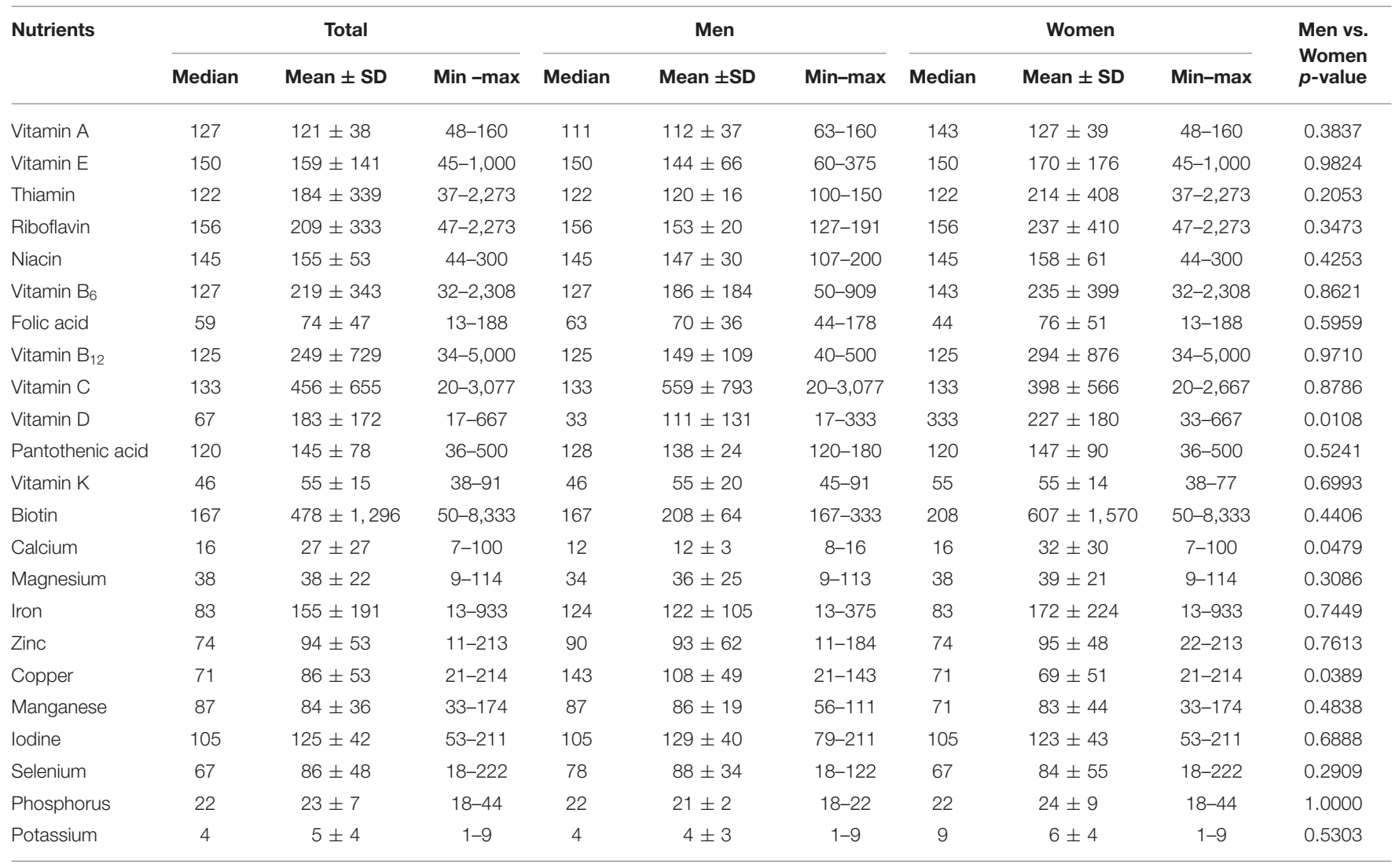

SD, standard deviation; *Mann-Whitney U test. 
frequent in adult Finns (32 and 58\%, respectively), Italians (41 and 56\%, respectively) and Germans (38 and 48\%, respectively). Spain had the lowest percentage of adults using supplements ( $8 \%$ men and $10 \%$ women). Results of our survey showed that frequency of food supplement consumption in Poland was low comparing to other European countries (30, 36-38).

In the United States, in 2007-2010, 49\% of adults reported using food supplements, it was more common in women than men. Older adults reported higher use than younger. Multivitamin-mineral products were the most common type of food supplements reported (16).

A study conducted in Novi Sad in Serbia in 2019 showed that $42.8 \%$ of respondents were using food supplements. Females were more likely to use supplements than males. Minerals, vitamins or their combinations were the most commonly used supplements (68.8\% of users). Contrary to the results of other studies, respondents with minimal and average incomes were more likely to use supplements compared to those with incomes above average (38).

In 2012-2013 there was investigated which nutrients are most often taken with supplements in Germany. The most frequently were consumed supplements containing vitamins: $\mathrm{C}$ (53\% of all supplement users), E (45\%) and B (37-45\%) and minerals: magnesium (59.2\%), calcium (37.0\%), zinc (33.6\%), and selenium $(23 \%)(39,40)$. In our survey, these nutrients were also often taken with supplements. However, supplements containing vitamin $\mathrm{D}$ and iron were also frequently used, while those containing calcium were consumed slightly less often.

As in Poland, in some countries survey on the consumption of food supplements was carried out in selected population groups.

In the United Arab Emirates (UAE) in 2018 the prevalence of food supplement use in college students was $35.6 \%$. Supplements were used more often by males than females. Protein, and vitamins $\mathrm{D}$ and $\mathrm{C}$ were the most commonly used by males. Females consumed mostly multi-vitamins and/or minerals, and single vitamins (41).

In Poland and other European countries, women use supplements more often $(30,36,37)$. Higher income does not always favor the use of supplements, as shown by studies from Serbia (38). In all countries, products containing vitamins and/or minerals are the most commonly used (30, 36-38).

It is very important to determine what nutrients are provided with the supplements and in what amounts. For this reason, it was a key element of our survey. However it is difficult to compare our data on vitamin and mineral intake from food supplements with the data of other authors. We analyzed what amounts of individual nutrients came from food supplements. The published data usually indicated mean intake of nutrients from food and from food and food supplements together (including food supplement users and non-users together) (30) or mean intake of nutrients from supplements only but in the group of all users (regardless used supplements contained an individual nutrient or not) $(39,40)$.

Supplementing the diet with vitamins and minerals in many cases may contribute to a better implementation of nutritional recommendations. However, consumers should be aware of the risk related to excessive intake of vitamins and minerals. Food supplements contain active ingredients that provide a physiological effect but also may cause adverse effect, especially in susceptible people (22). Some individuals use multiple supplements, which can result in potential interactions between them.

In our survey in some respondents, the intake of vitamins such as biotin, vitamin $B_{12}, C$, riboflavin, niacin and vitamin $B_{6}$ was several dozen times higher than the DRVs. In addition, in several subjects the intake of vitamin $\mathrm{B}_{6}$, $\mathrm{D}$ or magnesium was equal to or higher than the UL values. Moreover, some food supplement users could be at risk of interactions between the ingredients of supplements. $24 \%$ of respondents declared using more than one supplement during the day.

In the aforementioned survey in Germany a few subjects reached or exceeded the UL values through supplements alone. It concerned vitamin A, calcium, magnesium and zinc $(39,40)$.

Our research was conducted just before the COVID-19 pandemic and it is worth to see how the pandemic might affect supplement intake. As indicated the PLifeCOVID-19 Online Studies the intake of food supplements was influenced by the COVID-19 pandemic. The supplementation was initiated more frequently during the first than the second wave of the pandemic. Supplement users were primarily females, younger and better educated persons, living with the family, residents of urban areas. The most frequently supplemented nutrients were vitamin D, vitamin C, omega-3 fatty acids, folic acid, and magnesium. Compared to the pre-pandemic period, the consumption of supplements such as vitamins $\mathrm{C}$ and $\mathrm{D}$, zinc, garlic, ginger, or turmeric has increased. Improving immunity was the main reason to use food supplements (42).

However, current guidelines for the treatment of COVID19 do not suggest using food supplements (43). The decision to use food supplements should be preceded by a consultation with a physician or dietitian. Supplements are often used by people who care for a proper diet, which can provide them with adequate amounts of vitamins and minerals. In such cases, supplementation is not always necessary (44).

It is important to assess whether the diet is deficient in nutrients, in which nutrients and how the deficiency can be eliminated e.g., by modifying the diet, eating fortified food or using supplements. An assessment of the importance of food supplements in covering the requirements for individual nutrients in relation to its intake from all sources (food, fortified food, and supplements) is also crucial. The potential risk of adverse effects and interactions should also be considered.

There are several limitations regarding our survey. Analyses of mineral and vitamin intake from supplements concern subjects who used food supplements. As the percentage of them in the study population was small, the sample size was 178 subjects. However, the percentage of supplements users (10\%) was estimated on the basis of data for 1,831 respondents. In addition, the survey did not take into account all the factors associated with using supplements, including respondents' knowledge about supplements and the reasons for supplementation.

The survey has many strengths. The rate of supplement users was assessed in a group representative for the adult population in Poland. The data was collected using two methods (food propensity questionnaire and repeated 24 -h recall), which 
strengthens their credibility. The analyses concern only food supplements, but do not take into account OTC drugs. Detailed data on the name of the preparation and dose used was collected from each of the subjects. The survey provides relevant findings on vitamin and mineral intake with a warning around risk for excessive intakes.

\section{CONCLUSIONS}

According to the data collected a minority of adults in Poland declared the use of food supplements during the year. However, most of the supplement users consumed such products every day and food supplements were a significant source of vitamins and minerals. In this survey the gender of the respondents had an impact on the type of supplement used, the type of supplemented vitamins and minerals, as well as the intake and coverage of Dietary Reference Values in case of some of these nutrients. In some persons the intake of biotin, vitamin $\mathrm{B}_{12}, \mathrm{C}$, $\mathrm{B}_{6}$, riboflavin, niacin was higher than the reference values several dozen times. The intake above UL in a few cases relating to vitamin $\mathrm{B}_{6}$ and magnesium was observed. Due to the risk of excessive intake of vitamins and minerals from food supplements in combination with the diet, the consumption of these products should be monitored.

\section{DATA AVAILABILITY STATEMENT}

The raw data supporting the conclusions of this article will be made available by the authors, without undue reservation.

\section{REFERENCES}

1. World Health Organization. Fruit and vegetables for health: report of the Joint FAO/WHO Workshop on Fruit and Vegetables for Health, 1-3 September 2004. Kobe: World Health Organization (2005).

2. Mielgo-Ayuso J, Valtueña J, Huybrechts I, Breidenassel C, Cuenca-García M, De Henauw S, et al. Fruit and vegetables consumption is associated with higher vitamin intake and blood vitamin status among European adolescents. Eur J Clin Nutr. (2017) 71:458-67. doi: 10.1038/ejcn.2016.232

3. Bailey RL, West KP Jr, Black RE. The epidemiology of global micronutrient deficiencies. Ann Nutr Metab. (2015) 66:22-33. doi: 10.1159/0003 71618

4. Allen L, de Benoist B, Dary O, Hurrell R. Guidelines on Food Fortification With Micronutrients. World Health Organization and Food, Agriculture Organization of the United Nations (2006).

5. Food, Agriculture Organization of the United Nations. Food-Based Dietary Guidelines. Available online at: http://www.fao.org/nutrition/education/fooddietary-guidelines/regions/en/ (accessed May 28, 2021).

6. Tapsell LC, Neale EP, Satija A, Hu FB. Foods, nutrients, and dietary patterns: interconnections and implications for dietary guidelines. Adv Nutr. (2016) 7:445-54. doi: 10.3945/an.115.011718

7. Płudowski P, Karczmarewicz E, Bayer M, Carter G, Chlebna-Sokół D, CzechKowalska J, et al. Practical guidelines for the supplementation of vitamin D and the treatment of deficits in Central Europe. Endokrynol Pol. (2013) 64:319-27. doi: 10.5603/EP.2013.0012

8. Rusińska A, Płudowski P, Walczak M, Borszewska-Kornacka MK, Bossowski A, Chlebna-Sokół D, et al. Vitamin D supplementation guidelines for general population and groups at risk of vitamin D deficiency in Poland - recommendations of the polish society of pediatric endocrinology and diabetes and the expert panel with participation of national specialist

\section{ETHICS STATEMENT}

The studies involving human participants were reviewed and approved by the Bioethics Committee at the Institute of Food and Nutrition in Warsaw (opinion dated 04.06.2018). The patients/participants provided their written informed consent to participate in this study.

\section{AUTHOR CONTRIBUTIONS}

KS conceived the study, defined basic theses, wrote, and revised final version of the manuscript. AW contributed to study design, performed the statistical analysis, interpretation of the results, and wrote the manuscript. ER did the literature review and wrote the manuscript. IZ prepared data for analysis and wrote the manuscript. AG and MO prepared data for analysis. All authors contributed to the article and approved the submitted version.

\section{FUNDING}

The data for this paper came from the survey financially supported by European Food Safety Authority (No. OC/EFSA/DATA/2015/03 CT 2 and No. OC/EFSA/DATA/2015/03 CT 3) and Polish Ministry of Science and Higher Education (No. 3876/E-220/S/2018-1). This study was also performed under the project of National Institute of Public Health NIH - National Research Institute, Poland (FŻ-1/2021). consultants and representatives of scientific societies - 2018 update. Front Endocrinol. (2018) 9:246. doi: 10.3389/fendo.2018.00246

9. Zimmer M, Sieroszewski P, Oszukowski P, Huras H, Fuchs T, Pawlosek A. Polish society of gynecologists and obstetricians recommendations on supplementation during pregnancy. Ginekol Pol. (2020) 91:64453. doi: $10.5603 / \mathrm{GP} .2020 .0159$

10. Kehoe L, Walton J, Flynn A. Nutritional challenges for older adults in Europe: current status and future directions. Proc Nutr Soc. (2019) 78:22133. doi: $10.1017 /$ S0029665118002744

11. National Institute on Aging. Dietary Supplements for Older Adults. Available online at: https://www.nia.nih.gov/health/dietary-supplements-older-adults (accessed June 16, 2021).

12. Craig WJ, Mangels AR, American Dietetic Association. Position of the American dietetic association: vegetarian diets. J Am Diet Assoc. (2009) 109:1266-82. doi: 10.1016/j.jada.2009.05.027

13. Kamiński M, Kregielska-Narozna M, Bogdański P. Determination of the popularity of dietary supplements using Google search rankings. Nutrients. (2020) 12:908. doi: 10.3390/nu12040908

14. Perlitz H, Mensink GBM, Lage Barbosa C, Richter A, Brettschneider AK, Lehmann $\mathrm{F}$, et al. Use of vitamin and mineral supplements among adolescents living in Germany - results from EsKiMo II. Nutrients. (2019) 11:1208. doi: 10.3390/nu11061208

15. Sicińska E, Pietruszka B, Januszko O, Jakubowski S, Kielak-Biskupska K, Rolf $\mathrm{K}$, et al. Intake of vitamins and minerals from voluntarily fortified foods and/or dietary supplements in school adolescents in Central-Eastern Poland. Front Public Health. (2020) 8:504015. doi: 10.3389/fpubh.2020. 504015

16. Bailey RL, Gahche JJ, Miller PE, Thomas PR, Dwyer JT. Why US adults use dietary supplements. JAMA Intern Med. (2013) 173:35561. doi: 10.1001/jamainternmed.2013.2299 
17. Lentjes MAH. The balance between food and dietary supplements in the general population. Proc Nutr Soc. (2019) 78:97109. doi: $10.1017 /$ S0029665118002525

18. Directive 2002/46/EC of the European parliament and of the council of 10 June 2002 on the approximation of the laws of the member states relating to food supplements. J Eur. (2002) 183:51.

19. Ustawa $z$ dnia 25 sierpnia 2006 r. o bezpieczeństwie zywności i zywienia [Food and nutrition safety act from the 25th of August 2006]. Dz. U. (2006) 171:1225.

20. Rozporzadzenie Ministra Zdrowia z dnia 9 pazdziernika 2007 r. w sprawie składu oraz oznakowania suplementów diety [Regulation of the minister of health from the 9th of october 2007 on the composition and labeling of food supplements]. Dz. U. (2015) 2032.

21. EFSA. Overview on Tolerable Upper Intake Levels as derived by the Scientific Committee on Food (SCF) and the EFSA Panel on Dietetic Products, Nutrition and Allergies (NDA). Version 4. (2018). Available online at: https://www.efsa. europa.eu/sites/default/files/assets/UL_Summary_tables.pdf (accessed May 10, 2021).

22. Ronis MJJ, Pedersen KB, Watt J. Adverse effects of nutraceuticals and dietary supplements. Annu Rev Pharmacol Toxicol. (2018) 58:583601. doi: 10.1146/annurev-pharmtox-010617-052844

23. EFSA. General principles for the collection of national food consumption data in the view of a pan-European dietary survey. EFSA J. (2009) 7:1435. doi: 10.2903/j.efsa.2009.1435

24. EFSA. Guidance on the EU menu methodology. EFSA J. (2014) 12:3944. doi: 10.2903/j.efsa.2014.3944

25. Jarosz M, Rychlik E, Stoś K, Charzewska J, editors. Normy zywienia dla populacji Polski $i$ ich zastosowanie [Dietary Reference Values for the Polish population and their application]. Warszawa: Narodowy Instytut Zdrowia Publicznego - Państwowy Zakład Higieny (2020).

26. EFSA Scientific Committee on Food, Scientific Panel on Dietetic Products, Nutrition and Allergies. Tolerable Upper Intake Levels for Vitamins and Minerals. EFSA Scientific Committee on Food, Scientific Panel on Dietetic Products, Nutrition and Allergies (2006).

27. EFSA Panel on Dietetic Products, Nutrition and Allergies (NDA). Scientific opinion on the tolerable upper intake level of vitamin D. EFSA J. (2012) 10:2813. doi: 10.2903/j.efsa.2012.2813

28. EFSA Panel on Dietetic Products, Nutrition and Allergies (NDA). Scientific opinion on the tolerable upper intake level of calcium. EFSA J. (2012) 10:2814. doi: 10.2903/j.efsa.2012.2814

29. Szponar L, Sekuła W, Rychlik E, Ołtarzewski M, Figurska K. Badania indywidualnego spozycia zywności $i$ stanu odzywienia $w$ gospodarstwach domowych [Household Food Consumption and Anthropometric Survey]. Warszawa: Instytut Zywności i Zywienia. (2003).

30. Flynn A, Hirvonen T, Mensink GB, Ocké MC, Serra-Majem L, Stos K, et al. Intake of selected nutrients from foods, from fortification and from supplements in various European countries. Food Nutr Res. (2009) 53:151. doi: 10.3402/fnr.v53i0.2038

31. Waśkiewicz A, Sygnowska E, Broda G, Chwojnowska Z. The use of vitamin supplements among adults in Warsaw: is there any nutritional benefit? Rocz Panstw Zakl Hig. (2014) 65:119-26.

32. Ciszek P, Duma P. Analiza stosowania suplementów diety i świadomości zagrozeń wynikajacych $\mathrm{z}$ ich pobrania wśród studentów Uniwersytetu Rzeszowskiego [The analysis of the usage of dietary supplements and the awareness of threats resulting from their uptake among students of the University of Rzeszow]. Bromat Chem Toksykol. (2013) 46:404-12.

33. Wawryk-Gawda E, Budzyńska B, Lis-Sochacka M, Chylińska-Wrzos P, Zarobkiewicz M, Jodłowska-Jedrych B. Dietary supplements consumer assessment based on questionnaire survey. Przegl Epidemiol. (2018) 72:111-20.
34. Grzelak T, Suliga K, Sperling M, Pelczyńska M, Czyzewska K. Ocena stosowania suplementów diety wśród kobiet ciezarnych lub planujacych ciaze [Evaluation of dietary supplements use among pregnant women or planning pregnancy]. Forum Zaburzeń Metabolicznych. (2016) 7:8-15.

35. Wierzejska R, Wojda B. Folic acid supplementation in pregnancy and prevention of fetal neural tube defects. Przegl Epidemiol. (2020) 74:3629. doi: 10.32394/pe.74.29

36. Tetens I, Biltoft-Jensen A, Spagner C, Christensen T, Gille M, Bügel S, et al. Intake of micronutrients among Danish adult users and non-users of dietary supplements. J Food Nutr Res. (2011) 55:1-8. doi: 10.3402/fnr.v55i0. 7153

37. Giammarioli S, Boniglia C, Carratù B, Ciarrocchi M, Chiarotti F, Mosca $\mathrm{M}$, et al. Use of food supplements and determinants of usage in a sample Italian adult population. Public Health Nutr. (2013) 16:176881. doi: $10.1017 /$ S1368980012004314

38. Jovičić-Bata J, Grujičić M, Novaković B, Cović B. Epidemiology of dietary supplement use in Serbia: report from Novi sad. Complement Ther Med. (2019) 47:102228. doi: 10.1016/j.ctim.2019.102228

39. Willers J, Heinemann M, Bitterlich N, Hahn A. Vitamin intake from food supplements in a German cohort - is there a risk of excessive intake? Int J Vitam Nutr Res. (2014) 84:152-62. doi: 10.1024/0300-9831/a0 00202

40. Willers J, Heinemann M, Bitterlich N, Hahn A. Intake of minerals from food supplements in a German population-a nationwide survey. Food Nutr Sci. (2015) 6:205-15. doi: 10.4236/fns.2015.62021

41. Radwan H, Hasan HA, Ghanem L, Alnajjar G, Shabir A, Alshamsi A, et al. Prevalence of dietary supplement use and associated factors among college students in the united Arab emirates. J Community Health. (2019) 44:113540. doi: 10.1007/s10900-019-00700-2

42. Hamulka J, Jeruszka-Bielak M, Górnicka M, Drywień ME, Zielińska-Pukos MA. Dietary supplements during COVID-19 outbreak. Results of Google trends analysis supported by PLifeCOVID-19 online studies. Nxutrients. (2021) 13:54. doi: 10.3390/nu13010054

43. World Health Organization. Coronavirus Disease (COVID-19): Food Safety and Nutrition. (2020). Available online at: https://www.who.int/newsroom/q-a-detail/coronavirus-disease-covid-19-food-safety-and-nutrition (accessed August 14, 2021)

44. Dickinson A, MacKay D. Health habits and other characteristics of dietary supplement users: a review. Nutr J. (2014) 13:14. doi: 10.1186/1475-2891-13-14

Conflict of Interest: The authors declare that the research was conducted in the absence of any commercial or financial relationships that could be construed as a potential conflict of interest.

Publisher's Note: All claims expressed in this article are solely those of the authors and do not necessarily represent those of their affiliated organizations, or those of the publisher, the editors and the reviewers. Any product that may be evaluated in this article, or claim that may be made by its manufacturer, is not guaranteed or endorsed by the publisher.

Copyright (C) 2021 Stoś, Woźniak, Rychlik, Ziótkowska, Głowala and Ottarzewski. This is an open-access article distributed under the terms of the Creative Commons Attribution License (CC BY). The use, distribution or reproduction in other forums is permitted, provided the original author(s) and the copyright owner(s) are credited and that the original publication in this journal is cited, in accordance with accepted academic practice. No use, distribution or reproduction is permitted which does not comply with these terms. 